\title{
Toward Effective Learning Environment: Barriers of E-Learning Among Undergraduate Medical Students During COVID-19 Pandemic in a Developing Country
}

\author{
Nadira Mansour Hassan*, Shimaa M Koabar, Assmaa R Elgendy and Mohammad S Abouzeid \\ Public Health and Community Medicine Department, Faculty of Medicine, Tanta University, Tanta, Egypt \\ *Corresponding author: Nadira Mansour Hassan, Public Health and Community Medicine Department, Faculty \\ of Medicine, Tanta University, Tanta, Egypt
}

\section{ARTICLE INFO}

Received: 幽 August 17, 2021

Published: 幽 August 26, 2021

Citation: Nadira M H, Shimaa M K, Assmaa R E, Mohammad S A. Toward Effective Learning Environment: Barriers of E-Learning Among Undergraduate Medical Students During COVID-19 Pandemic in a Developing Country. Biomed J Sci \& Tech Res 38(3)-2021. BJSTR. MS.ID.006148.
Abstract

Background: At March 2020 there was great disruption of learning environment at medical schools in Egypt.COVID-19 pandemic leads to closure of all medical schools and sudden shift to exclusive e-learning. Although e-learning has its epidemiological benefits during this crisis, many barriers were encountered by medical students thathinder the learning environment to be effective.

This study aimed: to identify the barriers of exclusive e-learning mong medical students at Tanta University, Egypt, which could portray barriers in medical schools of developing countries. A cross-sectional survey was targeting the undergraduate medical students at Tanta University from1st to 6th academic years. The data were collected from 10th October through 14th November 2020 using a semi-structured online questionnaire. The respondents were 1137 students with a mean age of $20.9 \pm 1.5$ years. Females constituted

$72.6 \%$ of the participants and $48.7 \%$ were from low-income families. More than half $(59.7 \%)$ of participant students mostly use smartphone for e- learning. This study showed high magnitude of barriers' perception where the overall mean score of students' barrier perceptions toward e-learning was $69.46 \pm 12.33$ and only $27.7 \%$ of the participants prefer it. The barriers were multifactorial and interrelated. They include technological and infrastructure barriers, pedagogical, personal, sociodemographic and financial barriers.

Conclusion: The high magnitude of barrier perception indicated an urgent need to overcome them and create a more effective learning environment.

Keywords: Medical Students; E-Learning Barriers; COVID-19 Pandemic

\section{Introduction}

The emerging of COVID-19 as a deadly infectious disease and its declaration by world Health Organization on 11 March 2020 as a global pandemic have impacted all aspects of life seriously all over the world [1]. The education system was the one of the most affected sectors all over the world where physical and social distance became mandatory for infection control and safety of students, teachers, communities and nations as a whole [2]. At these times, traditional face to face learning environment became dangerous, all over the world, education institutions shut depriving about 1.5 billion of learners in 188 countries from all educational activities (United Nations Educational, Scientific, and Cultural Organization [3]. Medical schools were not an exception and to mitigate this tragedy, they rapidly shifted to exclusive e-learning. E-learning or online learning have in common the ability to use a computer connected to a network that offer the possibility to learn from anywhere, anytime, in any rhythm with any means [4]. Also, e-learning could be defined as using information technology (IT) to 
improve the quality of education [5]. Although e-learning has many advantages like anytime, anywhere feature which is required during COVID-19 crises, it needs many requirements to provide efficient and effective learning environment. It needs IT resources and IT skills for the institution, administrators, teachers and students [6]. Previous studies pointed that e- learning provides the learners with logistical and technical benefits in terms of flexibility, comfort, and ease of virtual learning. [7,8]. Other studies reported that rapid shift to e-learning showed many barriers from the students' point of view, like low internet access, lack of requisite digital equipment and accessories, high cost of efficient gadgets, physical problems like headache and eye strain [9-11]. Moreover, the practical nature of medical schools as the learning process cannot reach its full potential until the students practice what they learn, besides lack of direct interaction with patients which could lead to stress and mental problems to medical students [1,12]. For implementation of an efficient and effective e-learning environment a lot of time and cost is required for preparing the technological infrastructures, getting and maintaining devices and equipment, training human resources and developing online content [1]. In Egypt, the Ministry of High Education decided to continue the learning process during COVID-19 pandemic and implement e-learning at governmental educational institutions. Tanta Medical School is the nationally accredited medical school in middle delta, Egypt. Fortunately, it had implemented a special program called Competency Based Medical Bachelor Program (CBMBP) since 2018 in which blended learning was applied. For providing this program Tanta medical school has paid a great effort to be partly equipped with the human and nonhuman resources and frequent assessment and feedbacks from students and teachers were carried out. CBMP is a private program with small number of students, so implementation of exclusively e-learning on the free mainstream program with its large number of students could be considered a different learning environment especially from the students' point of view and could has barriers shared with other medical schools in Egypt. Detecting barriers of exclusive e- learning that encountered undergraduates' medical students in Tanta University, could contribute in improving the quality of learning environment in medical education.

\section{Objective of the Study}

To explore barriers of exclusive e-learning among undergraduate medical students in Tanta University that

hinder effective learning environment.

\section{Methods}

Study setting: faculty of medicine, Tanta University, the oldest and nationally accredited medical school in Delta region of Egypt and accommodated for about 6000 undergraduate medical students. It could represent an educational institution in a resource limited country during the COVID-19 crisis, giving insights into the barriers in other medical schools in developing countries.

\section{Study Design, Subjects and Duration}

The study employed a descriptive cross-sectional design targeting the undergraduate medical students at Tanta University from 1 st to $6^{\text {th }}$ academic years. The study was carried out at the beginning of the first semester of the scholastic year 2020/2021 after depending exclusively on e-learning to continue the educational process at the previous academic year due to COVID-19 pandemic. Data collection took place from $10^{\text {th }}$ October through $14^{\text {th }}$ November 2020.

\section{Study Tool}

The data was collected via an online survey Google Form platform. Each academic year was divided into groups and each group has a leader who creates a WhatsApp application group which includes all students in his group. Those leaders were contacted, and the purpose of the study was explained. The leaders requested to send the link of the Google sheet containing the questionnaire to their groups. The Google sheet was settled to allow only one response from the same person to prevent duplication. Objective of the study was explained at the beginning of the questionnaire to all students, and their enrollment was after their consent to participate in the study. The questionnaire included two main parts. Part one related to personal characteristics: age, sex, year of study, residence, family income, the device mostly used for e-learning (smart phone, laptop or desktop). Part two was developed by the researchers based on discussion with students and previous relevant literatures $[10,11]$. It included 19 questions to identify the barriers that the students may exposed to due to exclusive e-learning and to assess their degree of perception of these barriers. The questions were designed in 5-point Likert scale ranged from strongly disagree (1) to strongly agree (5). Higher scores (agree and strongly agree expressed a barrier state. The study Tool was sent to three experts for validation, and it was found to be valid after some modifications. Cronbach's alpha was calculated, and it was 0.85. After development of the questionnaire and before starting the actual data collection, a pilot study was conducted. It was done on 20 students (not included in the study). The Data was collected anonymously. Privacy and confidentiality were assured.

\section{Data Management}

The rating scale consists of 19 items with five points Likert scale ( 1 to 5 ) was converted into three points scale where 1 and 2 scales were merged into one item expressing strongly disagree and disagree, 4 and 5 scales were merged to express agree and strongly agree in one scale. Each of the 19 items with mean score of 3 is an area of neutral perception, $>3$ is true barrier perception and $<3$ is not a barrier for e- learning. Minimum score was 19 and maximum score was 95. The score of the items was summed-up and the total divided by the number of the items, to calculate the mean score for barriers of e-learning.

\section{Statistical Analysis}

The collected data were encoded organized, tabulated, and statistically analyzed using statistical package for social studies (SPSS) version 22 created by IBM, Chicago, Illinois, USA). Quantitative data were presented as mean \pm standard deviation and mode, while qualitative data were presented as frequency and percentage. The student $\mathrm{s}$ t-test was used for comparisons of mean 
values between two groups and the ANOVA test was performed to compare means of more than two groups. The level of significance adopted at $\mathrm{p}<0.05$.

\section{Ethical Considerations}

Participants were informed of the procedures and purpose of the study, and how they will benefit from the study. Data was collected anonymously with respect to privacy and confidentiality of participants and formal consent was obtained. Approval of the Ethical Committee of Scientific Research of Faculty of Medicine, Tanta University was obtained. All procedures performed in this study were in accordance with the1964 Helsinki declaration and its later amendments or comparable ethical standards. Also, it was in accordance with the ethical standards of the Ethical Committee of Scientific Research of Faculty of Medicine, Tanta University, Federal Wide Assurance (FWA00022834), (IRB 0010038) and approved (reference number 34320)

\section{Results}

The number of respondents was 1137 medical students with a mean age of $20.9 \pm 1.5$ years. Females constituted $72.6 \%$ of the participants, $41.3 \%$ from urban resident. The family income of

Table 1: Characteristics of the studied medical students.
$48.7 \%$ the participants was $\leq 3000$ LE. More than half $(59.7 \%)$ of participant students mostly use smartphone for e- learning (Table 1 ). The top ten barriers (agree and strongly agree) were improper internet access (83.2\%), the need of stable electricity and proper setup (computer and earphone (80.9\%), lack of feeling affiliation to the college (72.9\%), lack of student teacher interaction $(71.5 \%)$, students' anxiousness about their clinical future (68.9\%), lack of discussion among students (65.9\%), cost of internet recharge (65.4\%), anxiety and stress due to less technical assistance (65\%) and the physical problems like headache, eye strain fatigue that were usually occurred due to prolonged use of devices for e-learning (62.3\%), lack in motivation(61.3\%). 0nly $27.7 \%$ reported that they prefer e - learning and think it is a better method for teaching medicine (Table 2). Individual item-wise analysis of the rating scale pointed that all of the items on respondents' barrier perception to e-learning scored $>3$ (Table 3). Moreover, (Table 4) showed that the Score of overall students' barrier perception to exclusive e- learning was $69.46 \pm 12.33$ (73.14\% of maximum score). (Table 5): shows that age group 17 - 19 years and females had significantly different higher scores $(\mathrm{p}<0.001)$, urban resident student significantly had lower scores than rural and semi-urban students $(\mathrm{p}=0.022)$, the difference between

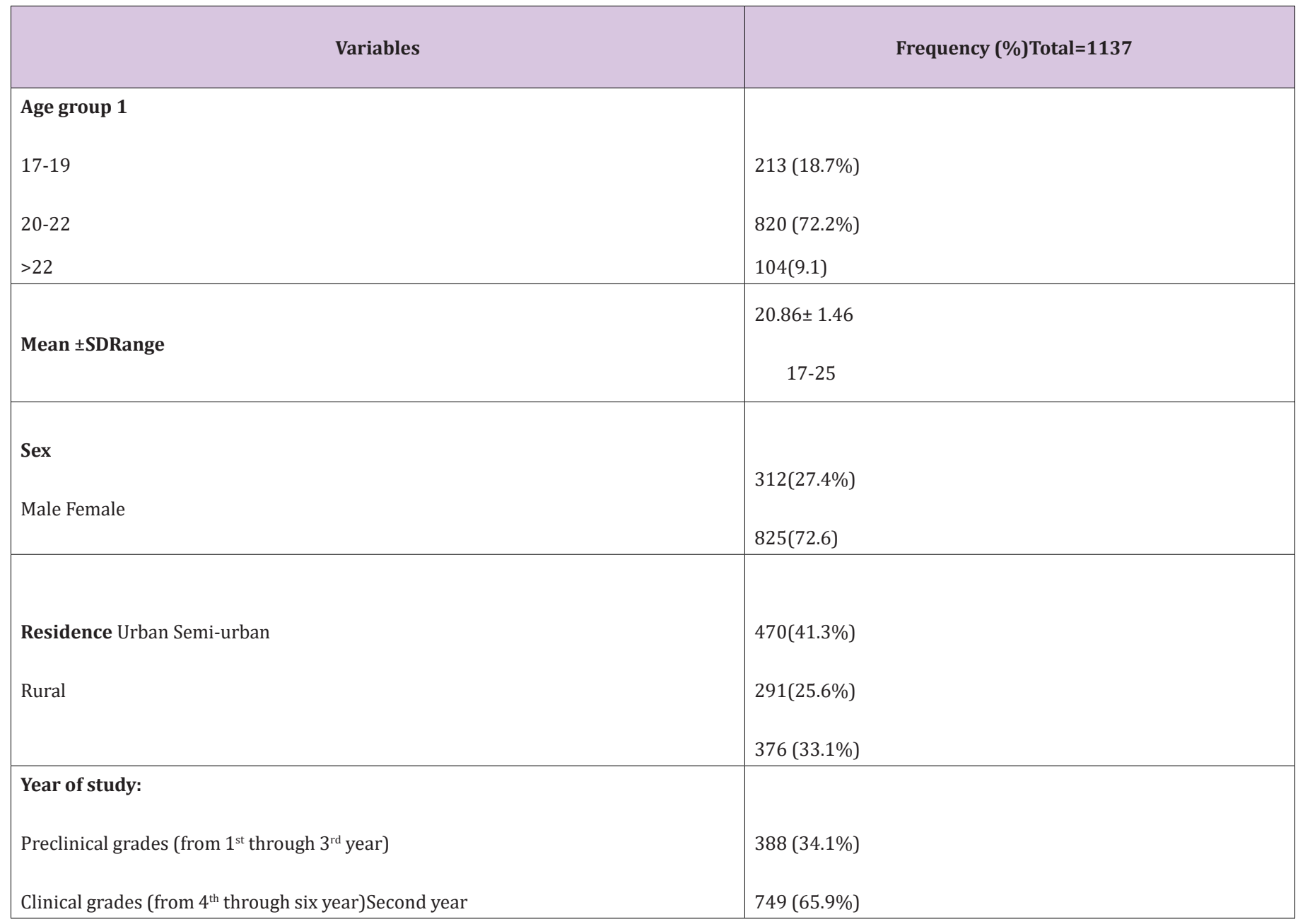




\begin{tabular}{|l|l}
\hline Family income1 (incom1) & $554(48.7 \%)$ \\
$\leq 3000$ LE & $583(51.3 \%)$ \\
\hline Devise mostly used for e learning: & \\
Desktop Laptop smartphone & $41(3.6 \%)$ \\
& $417(36.7 \%)$ \\
& $679(59.7 \%)$
\end{tabular}

Table 2: Perception of barriers among studied medical students.

\begin{tabular}{|c|c|c|c|}
\hline \multirow[b]{2}{*}{ Statements } & \multicolumn{3}{|c|}{ Degree of perception of e- learning barriers } \\
\hline & $\begin{array}{r}\text { Strongly } \\
\text { disagree \& } \\
\text { disagree }\end{array}$ & Neutral & $\begin{array}{c}\text { Agree \& } \\
\text { Strongly } \\
\text { agree }\end{array}$ \\
\hline e-learning requires strong internet access & $55(4.9 \%)$ & $136(12 \%)$ & $946(83.2 \%)$ \\
\hline $\begin{array}{l}\text { e- learning dependents on stable electricity and need aproper setup (computer } \\
\text { and earphone) }\end{array}$ & $63(5.5 \%)$ & $154(13.6 \%)$ & $920(80.9 \%)$ \\
\hline $\begin{array}{l}\text { Direct classes are important for feeling affiliation to the } \\
\text { college }\end{array}$ & $105(9.2 \%)$ & $203(17.9 \%)$ & $829(72.9 \%)$ \\
\hline e- learning is lacked in student teacher interaction & $147(12.9 \%)$ & $178(15.7 \%)$ & $812(71.4 \%)$ \\
\hline I am anxious about my clinical future due to e-learning & $134(11.8 \%)$ & $220(19.3 \%)$ & $783(68.9 \%)$ \\
\hline e- learning is lacked in discussion among students & $180(15.8 \%)$ & $207(18.2 \%)$ & $750(65.9 \%)$ \\
\hline e- learning is very costly in terms of internet recharge & $144(12.7 \%)$ & $249(21.9 \%)$ & $744(65.4 \%)$ \\
\hline $\begin{array}{l}\text { e- learning creates anxiety or stress due to less } \\
\text { technical assistance }\end{array}$ & $147(16.4 \%)$ & $211(18.6 \%)$ & $739(65 \%)$ \\
\hline $\begin{array}{l}\text { e- learning usually leads to more physical problems like } \\
\text { eye pain, fatigue, and headache }\end{array}$ & $193(17 \%)$ & $236(20.7 \%)$ & $708(62.3 \%)$ \\
\hline e-learning lacked in motivation & $207(18.2 \%)$ & $233(20.5 \%)$ & $697(61.3 \%)$ \\
\hline e-learning is not fruitful like direct classes & $189(16.6 \%)$ & $265(23.3 \%)$ & $683(60.1 \%)$ \\
\hline e- learning commonly has more interruptions & $227(20 \%)$ & $240(21.1 \%)$ & $670(58.9 \%)$ \\
\hline e-learning site is not available at all time & $212(18.6 \%)$ & $270(23.8 \%)$ & $655(57.6 \%)$ \\
\hline e-learning is lacked in student evaluation & $217(19.1 \%)$ & $266(23.4 \%)$ & $663(57.5 \%)$ \\
\hline e- learning is lacked in technical knowledge & $226(19.9 \%)$ & $267(23.5 \%)$ & $644(56.6 \%)$ \\
\hline $\begin{array}{l}\text { e- learning leads to reluctance on following up the } \\
\text { lectures and curriculum }\end{array}$ & $145(12.8 \%)$ & $364(32 \%)$ & $628(55.2 \%)$ \\
\hline e-learning leads to loss of lecturer as a role model & $247(21.7 \%)$ & $269(23.7 \%)$ & $621(54.6 \%)$ \\
\hline e- learning is lacked in control over the group & $254(22.3 \%)$ & $317(27.9 \%)$ & $566(49.8 \%)$ \\
\hline $\begin{array}{l}\text { I prefer e - learning and I think it is a better method } \\
\text { for medical education }\end{array}$ & $476(41.9)$ & $346(30.4 \%)$ & $315(27.7)$ \\
\hline
\end{tabular}


Table 3: Mean score of individual items of rating scale of students' perception of e-learning ( $n=1137)$.

\begin{tabular}{|c|c|c|}
\hline Items & Mean \pm SD & Mode \\
\hline e-learning requires strong internet access & $4.20 \pm 0.89$ & 5 \\
\hline $\begin{array}{l}\text { e learning dependents on stable electricity and need a proper setup (computer and } \\
\qquad \text { earphone) }\end{array}$ & $4.08 \pm 0.88$ & 4 \\
\hline Direct classes are important for feeling affiliation to the college & $3.83 \pm 0.96$ & 4 \\
\hline e- learning is lacked in student teacher interaction & $3.83 \pm 1.04$ & 4 \\
\hline I am anxious about my clinical future & $3.84 \pm 1.05$ & 4 \\
\hline e- learning lacked peer discussion & $3.68 \pm 1.08$ & 4 \\
\hline e- learning needs frequent internet recharge which is very costly & $3.80 \pm 1.06$ & 4 \\
\hline e-learning creates anxiety or stress due to less technical assistance & $3.68 \pm 1.08$ & 4 \\
\hline $\begin{array}{l}\text { e-learning usually leads to more physical problems like eye strain, headache and fatigue } \\
\qquad \text { on prolonged use of electronic devices }\end{array}$ & $3.71 \pm 1.15$ & 4 \\
\hline e-learning lacked in motivation & $3.59 \pm 1.06$ & 4 \\
\hline e-learning is not fruitful like direct classes & $3.60 \pm 1.1$ & 4 \\
\hline e- learning commonly has more interruptions & $3.55 \pm 1.1$ & 4 \\
\hline e- learning site is not available at all time & $3.54 \pm 1.06$ & 4 \\
\hline e-learning lacked in student evaluation & $3.50 \pm 1.05$ & 4 \\
\hline e- Q15: e-learning requires technical knowledge more than I have & $3.50 \pm 3.05$ & 3 \\
\hline e- learning leads to reluctance on following up the lectures and curriculum & $3.53 \pm 0.95$ & 4 \\
\hline e-learning leads to loss of lecturer as a role model & $3.43 \pm 1.08$ & 4 \\
\hline e- learning lacked in control over the group & $3.37 \pm 1.07$ & 4 \\
\hline $\begin{array}{l}\text { I don't prefer e - learning for medical education, it is not a better method for medical } \\
\text { education }\end{array}$ & $3.22 \pm 1.13$ & 3 \\
\hline
\end{tabular}

Table 4: Score of overall students' barrier perception to exclusive e- learning $(n=1137)$.

\begin{tabular}{|c|c|c|c|c|}
\hline Characteristics & No. of items & $\begin{array}{c}\text { Obtainable } \\
\text { score }\end{array}$ & Mean \pm SD & Mean percent \\
\hline barriers' perception of participants to & & $22-95$ & & \\
\hline exclusive e- learning & 19 & $19-95$ & $69.46 \pm 12.33$ & 73.14 \\
\hline
\end{tabular}


Table 5: Students' barrier perception score to e-learning by their background characteristics ( $\mathrm{n}=1137)$.

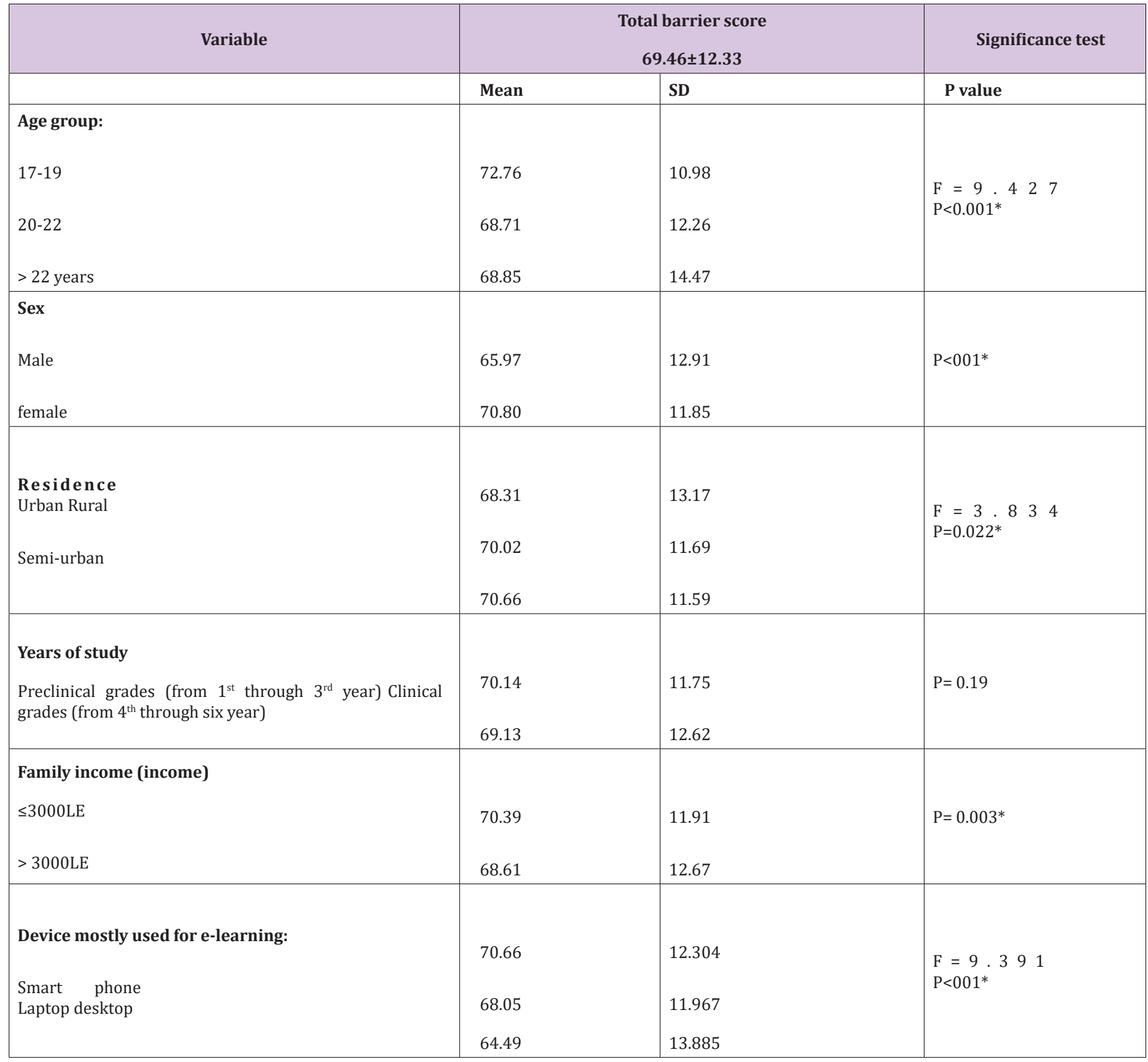

the preclinical $\left(1^{\text {st }}\right.$ through $\left.3^{\text {rd }}\right)$ and clinical ( $4^{\text {th }}$ through $\left.6^{\text {th }}\right)$ academic years was not significant $(p=0.19)$. Those students that their family income $\leq 3000 \mathrm{LE}$ had significant higher score barrier $(\mathrm{P}=0.024)$ and those use smartphones for e-learning were had significant high scores than others $(\mathrm{P}<001)$.

\section{Discussion}

Given the growing importance of application of e- learning in medical education during COVID-19 pandemic, it is critical to understand the barriers that faced the students and hinder the learning environment to be effective. This research output can be used as an input to improve the quality of medical education. Although e- learning provides resilient and innovative solution at the time of COVID-19 crisis to combat the disruption of medical education, only $27.7 \%$ of the participants prefer it and the overall mean score of students' barrier perceptions towards e-learning in the present study was $69.46 \pm 12.33$. This pointed that there are many barriers in the online learning environment. The fundamental barriers revealed in the present study are classified into technological and infrastructure barriers, pedagogical barriers, personal barriers, sociodemographic and financial barriers. Technological and infrastructure problems were lies on top of barriers to effective e learning environment where more than eighty percent of respondents reported that requirement of strong internet access and need for stable electricity were the prime barriers. This was in agreement with the results of many previous studies rolled medical and nursing students in India, Uganda and Poland $[10,13,14]$. 
Also, a considerable percentage of students at the present study reported that e- learning commonly has more interruption; the e-learning site is not available all the time together with lack of control over groups. This was in line with the findings of medical and nursing students in India and Egypt $[11,15]$. Virtual e- learning environment has many pedagogical problems. It was reported that conventional direct face to face learning environment allows better interaction between students and the staff so, they are motivated and inspired to learn $[15,16]$. Together with discussion and peer review among students with feelings of gatherings in sharing opinions and learning experiences [17-19]. All these aspects were lacked to great extent in the virtual learning environment. Moreover, absence of lecturer as a role model which is essential for professionalism of medical students. All these barriers were expressed by most of the respondents in the current study. Also, this could explain the high magnitude of personal barriers reported by the participants who perceived e-learning not fruitful like direct learning, lack of true evaluation and diminished affiliation to the college. Together with lack of time management skill and technical knowledge, $[18,20,21]$ the advantages of time and flexibility of e-learning could be converted to disadvantages and lead to students' reluctance in following their lectures and curriculum $[18,19]$.

Moreover, $62.2 \%$ of respondents of the present study complaining of physical problems like fatigue, headache and problems related to eye stain on long duration use of e-learning devices and this was in agreement of the findings of previous studies $[17,18,22]$. One of World Health organization (WHO) strategies to contain COVID-19 pandemic is suspension of clinical teaching at medical schools and hospitals to protect the students and the community [23]. This strategy deprives the medical students from acquiring their clinical training skills and delivers two punch blows to medical students. First: loss of the critical role of studentpatient interactions during medical training which is essential for development of professional attitudes, skills and culture sensitivity [24] Second: the student as a learner is a part of the team of clinical environment, he needs supervision and formation of professional identity which depends mainly on teaching and role modeling in these settings [25]. So, it was not surprising to find that more than two thirds of the respondents of the current study were anxious about their clinical future with item mean score $3.84 \pm 1.05$. This was highlighted in many studies in different nations worldwide either satisfied with e-learning in medical education $[17,26]$ or not $[14,20,27]$. The students explained this feeling by different statements all were means that clinical setting is essential for medical education and cannot be fully replaced by online learning even with the professional use of social media. One of best statements said by one of participants of study carried out at India was "There is great difference to play football on ground and in mobile" [17]. As regards the sociodemographic and financial barriers, the current study pointed to significant differences in the total score of perception of e- learning across characteristics of students, including age group 17-19 years who are usually at the first and second year of study and find difficulty in dealing with the new curriculums of medical education (they are belonged to the new $5+2$ program). Also, females expressed high barrier scores, and this was in agreement with the findings of Gehan and Nahed (2020).

Also, there is significant difference between the students regarding their residence where those from rural and semiurban areas had higher scores. This was in agreement with the findings of Baticulon et al. (2020), Nartiningrum and Nugroho (2020) $[19,28]$. Rural and remote areas usually have poor internet connections, quality and coverage [27] and this could lead to inequities in engaging in e-learning classes with its subsequent feeling of frustrations and stress as suggested by Sharma et al. 2020. On the other hand, the financial cost of e-learning should not be underestimated as an important barrier hindering effective learning for students of low-income families. This was documented by about two thirds of respondents in the present study with mean item score $3.8 \pm 1.06$. Given the family income of nearly half of respondents and the use of smartphone as the devise mostly used for online learning by $59.7 \%$ of participants, the cost barrier of net recharge could be understood. The cost of recharge of internet quota as a barrier hindering e- learning was also revealed by Amir et al. (2020) and Ramij and sultana (2020) [18,29]. This may lead to inequities with stress and sense of frustration that could affect their academic progress. However, there was no significant difference in the total barrier score means between student group at 1st through 3rd year and those from 4th through 6th year of study. This could be explained by both groups have many problems with e-learning suggested by the high mean total scores $(70.14 \pm 11.75$ and $69.13 \pm 12.62$ respectively) but the problems were different in nature. Students at the first three years of study are related to new five-year medical education program which is an integrated recent program with its first application and new problems and students at the second group are related to the old six medical program and they were in the clinical years with its problems with e-learning as these years depends mainly on rotations between hospital departments and patient-based education.

The present study characterized by the high magnitude of barriers' perception so, it was not surprising to find that only $27.7 \%$ of the participants preferred exclusive e-learning for medical education with a mean score of $3.22 \pm 1.13$ denoting that the respondents were not satisfied with exclusive e- learning as a better method for medical education and acquiring clinical skills. Previous studies suggested that with the sudden shift to e-learning due to COVID-19 pandemic and depending on it as the only method for teaching during the period of lockdown, the students comparing their previous experience with face-to-face method with the current recent one. Moreover, these studies showed that students still prefer the conventional method $[14,30]$. Thus, the evaluation of e-learning as an effective method for medical education is of paramount important for further improvement. E-learning was an option for medical education before COVID-19 but now it becomes a necessity, so it is mandatory for all medical institutions to overcome the barriers and improve the students' perceptions towards e-learning [31]. The use of synchronous learning should be enforced where there is use of social learning environment and answering questions live as were recommended by McBrien et al. 
2009, Muir et al. 2020 and Morawo et al. 2020 [32-34]. Thus, active communication between students and lecturers occurred and involvement of students increased creating a more active learning environment improve students' perception to e-learning. Beyond COVID-19 crisis, blended learning is a good option suggested by students in previous studies $[17,18,21]$ and have the advantages of both virtual and conventional learning.

\section{Strengths and Limitations}

The strength of this study lies on its large sample recruited from all years of medical education from 1 st to $6^{\text {th }}$ academic years during a critical period of the COVID-19 pandemic including two types of medical education programs. Limitations of the study: it was carried out at the beginning of the first semester of the scholastic year 2020/2021 just after depending exclusively on e-learning so their response may exaggerate the level of barriers due to inability to accommodate with this new situation for education which may be considered as shock for those who did not have experience on it.

\section{Conclusion}

Barriers to effective e-learning environment among Tanta Medical School could portray barriers in developing country medical schools. The findings of the present study emphasized that barriers of exclusive e-learning are multifactorial and interrelated during COVID-19 crisis. These barriers include technological and infrastructure barriers, pedagogical, personal, sociodemographic and financial barriers. There was high magnitude of barriers' perception and only $27.7 \%$ of respondents prefer exclusive e-learning as a better method for medical education. So, there is an urgent need to overcome these barriers and create a more effective learning environment.

\section{Compliance with Ethical Standards}

All procedures performed in this study were in accordance with the1964 Helsinki declaration and its later

amendments or comparable ethical standards. Also, it was in accordance with the ethical standards of the Ethical Committee of Scientific Research of Faculty of Medicine, Tanta University, Federal Wide Assurance (FWA00022834), (IRB 0010038) and approved (reference number 34320).

\section{Informed Consent}

Informed consent was obtained from all individual participants included in the study. The participants were told about the purpose of the study, and they were informed that the data would be used for scientific purposes only. They were also given the right to refuse or participate in the study.

\section{Consent for Publication}

Not applicable.

\section{Availability of Data and Material}

Available from the corresponding author on reasonable request.

\section{Competing Interest}

The authors declare that they had no competing interests.

\section{Funding}

No available fundus.

\section{Authors' Contribution}

Nadira Mansour Hassan: Conceptualization, methodology, formal analysis, data curation, writing the original draft and editing, Mohamed Salama Abozeid: reviewed the findings and final manuscript for submission, Shimaa Mohammad Koabar: data collection and Assmaa Rashed Elgendy: formatting the questionnaire at google and data collection. All authors read and approved the final manuscript.

\section{Acknowledgement}

Thanks to all participant students, faculty of Medicine, Tanta University.

\section{References}

1. Dhawan S (2020) Online learning: a panacea in the time of COVID-19 crisis. J Edu Technol System 49(1): 5-22.

2. Khasawneh AI, Humeidan AA, Alsulaiman JW, Bloukh S, Ramadan M, et al. (2020) Medical students and Covid-19: knowledge, attitudes, and precautionary measures. a descriptive study from Jordan. Front Public Health 8: 253.

3. UNESCO (2020) Distance education in the corona virus pandemic.

4. Cojocariu VM, Lazar I, Nedeff V, Lazar G (2014) SWOT analysis of e-learning educational services from the perspective of their beneficiaries. Procedia Soc Behav Sci 116: 1999-2003.

5. Howlett D, Vincent T, Gainsborough N, Fairclough J, Taylor N, et al. (2009) Integration of a case-based online module into an undergraduate curriculum: what is involved and what is effective? E-Learning and Digital Media 6(4): 372-384.

6. Ali W (2020) Online and remotes learning in higher education institutes: a necessity in light of Covid-19 pandemic. Higher Edu Studies 10(3): 1625.

7. Asiry MA (2017) Dental students' perceptions of an online learning. Saudi Dent J 29 (4): 167-170.

8. Al-Samarraie H, Teng BK, Alzahrani AI, Alalwan N (2018) E learning continuance satisfaction in higher education: a unified perspective from instructors and students. Studies Higher Edu 43(11): 2003-2019.

9. Naresh B, Reddy BS (2015) Challenges and opportunity of e-learning in developed and developing countries- a review. Int J Emerg Res Man Technol 4(6): 259-262.

10. Gaur R, Mudgal SK, Dharni IT, Sharma R, Suyal N (2020) Barriers encountered during online classes among undergraduate nursing students during COVID-19 pandemic in India. Int J Res Med Sci 8(10): 3687-3693.

11. Abd El-Hamed Diab GM, Elgahsh NF (2020) E-learning during COVID-19 pandemic: obstacles faced nursing students and its effect on their attitudes while applying it. American J Nur Sci 9(4): 295-309.

12. Sharma D, Bhaskar S (2020) Addressing the Covid-19 burden on medical education and training: the role of telemedicine and tele-education during and beyond the pandemic. Front Public Health 8: 589669.

13. Olum R, Atulinda L, Kigozi E, Nassozi DR, Mulekwa A, et al. (2020) Medical Education and e-learning during covid-19 pandemic: awareness, at- 
titudes, preferences, and barriers among undergraduate medicine and nursing students at Makerere University, Uganda. J Med Edu Curricular Develop 7: 1-9.

14. Bączek M, Zagańczyk-Bączek M, Szpringer M, Jaroszyński A, Wożakowska-Kapłon B (2021) Students'

perception of online learning during the COVID-19 pandemic: a survey study of Polish medical students. Medicine(Baltimore) 100(7): (e24821).

15. Suryawanshi DM, Venugopal R (2020) Preferences, perceptions and barriers to E-learning among medical students during COVID-19 pandemic lockdown in India. Int J Community Med Public Health 7(10): 41004104

16. Yusuf N, Al-Banawi N (2013) The impact of changing technology: the case of E-learning. Contemp Issues Educ Res 6(2): 173-180.

17. Shetty S, Shilpa C, Dey D, Kavya S (2020) Academic crisis during COVID 19: online classes, a panacea for imminent doctors. Indian J Otolaryngol Head Neck Surg pp. 1-5.

18. Amir LR, Tanti I, Mahran DA, Wimardhani WS, Julia V, et al. (2020) Student perspective of classroom and distance learning during COVID-19 pandemic in the undergraduate dental study program Universities Indonesia. BMC Med Educ 20(1): 392.

19. Nartiningrum N, Nugroho A (2020) Online learning amidst global pandemic: efl students' challenges, suggestions, and needed materials. English Franca 4(2): 115-140.

20. Singh R, Subedi M, Pant S, Rai P, Gupta KK, et al. ( 2021) Perception towards online teaching-learning in medical education among medical students during COVID-19 Outbreak in Nepal: a descriptive cross-sectional Study. J Nepal Med Assoc 59(234): 128-133.

21. Rajab MH, Gazal AM, Alkattan K (2020) Challenges to online medical education during the COVID-19 pandemic. Cureus 12(7): e8966.

22. Octaberlina LR, Muslimin AI (2020) EFL students perspective towards online learning barriers and alternatives using moodle/google classroom during COVID-19 pandemic. Int J Higher Educ 9(6): 1-9.

23. WHO Coronavirus disease (COVID-19) Advice for the public.

ISSN: 2574-1241

DOI: 10.26717/BJSTR.2021.38.006148

Nadira Mansour Hassan. Biomed J Sci \& Tech Res

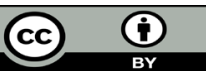

This work is licensed under Creative Commons Attribution 4.0 License

Submission Link: https://biomedres.us/submit-manuscript.php
24. Ferrel MN, Ryan JJ (2020) The impact of COVID-19 on medical education. Cureus 12(3): e7492.

25. Rose S (2020) Medical student education in the time of COVID-19. JAMA 323(21): 2131.

26. Ibrahim NK, Al Raddadi R, Al Darmasi M, Al Ghamdi A, Gaddoury M, et al. (2021) Medical students' perceptions and acceptance of e-learning during COVID-19 closure in King Abdulaziz University, Jeddah. J Infect Public Health 14(1): 17-23.

27. Al-Balas M, Al-Balas HI, Jaber HM, Obeidat K, Al-Balas H, et al. (2020) Distance learning in clinical medical education amid COVID-19 pandemic in Jordan: current situation, challenges, and perspectives. BMC Medic Educ 20: 341.

28. Baticulon RE, Sy JJ, Alberto NR, Baron MBC, Mabulay REC, et al. (2021) Barriers to online learning in the time of COVID-19: a national survey of medical students in the Philippines. Med Sci Educ pp. 1-12.

29. Ramij MG, Sultana A (2020) Preparedness of Online Classes in Developing Countries amid COVID-19 Outbreak: A Perspective from Bangladesh. SSRN J pp. 26.

30. Adnan M, Anwar K (2020) Online learning amid the COVID-19 pandemic: students' perspectives. J Pedagog Res 2(1): 45-51.

31. Dost S, Hossain A, Shehab M, Abdelwahed A, Al-Nusair, et al. (2020) Perceptions of medical students towards online teaching during the COVID-19 pandemic: a national cross- sectional survey of 2721 UK medical students. BMJ Open 10(11): e042378.

32. McBrien JL, Cheng R, Jones P (2009) Virtual spaces: employing a synchronous online classroom to facilitate student engagement in online learning. IRRODL 10(3): 605.

33. Muir S, Tirlea L, Elphinstone B, Huynh M (2020) Promoting classroom engagement through the use of an online student response system: a mixed methods analysis. J Statist Educ 28(1): 25-31.

34. Morawo A, Sun C, Lowden M (2020) Enhancing engagement during live virtual learning using interactive quizzes. Med Educ 54(12): 1188.

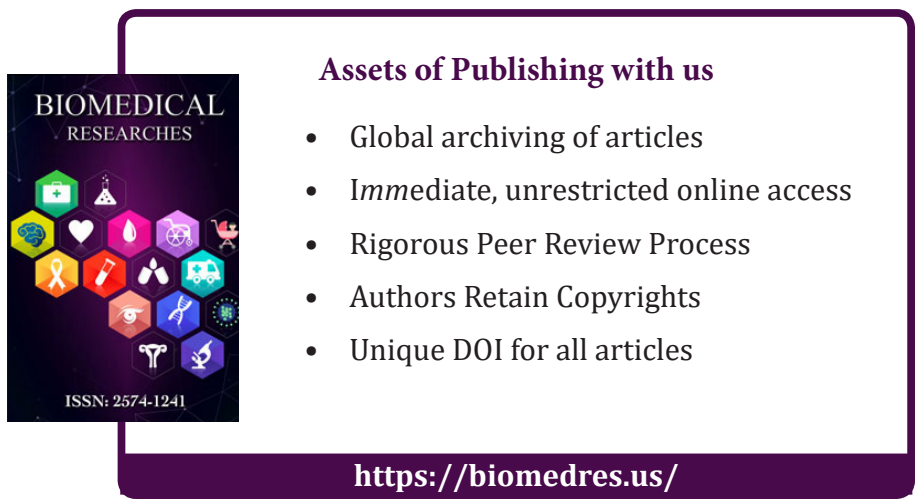

Copyright@ Nadira Mansour Hassan | Biomed J Sci \& Tech Res | BJSTR. MS.ID.006148. 